\title{
Editorial
}

Dermatology

\section{Neutrophilic Cutaneous Lupus Erythematosus}

\author{
At the Edge between Innate and Acquired Immunity?
}

\author{
Dan Lipsker $^{\mathrm{a}}$ Jean-Hilaire Saurat ${ }^{\mathrm{b}}$

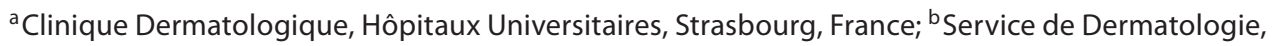 \\ Hôpitaux Universitaires, Genève, Suisse
}

It is always a challenging task to classify inflammatory diseases [1]. Often, in general internal medicine, a primary goal is to classify a patient with a complex constellation of signs in either a tumoral, infectious or inflammatory disease category. The non-tumoral and noninfectious inflammatory diseases are usually thought of as being mainly related to auto-immune diseases. However, many inflammatory diseases which are neither tumoral nor infections do not involve auto-immunity in their pathogenesis. They lack significant major histocompatibility complex (MHC) associations and there is an absence of auto-antibodies or significant T-cell-mediated auto-immunity.

The immune system is classically separated into two largely interconnected and overlapping types of responses. First comes the immediate response, involving epithelia, preformed mediators and some cells belonging to the immune system, like natural killer cells and dendritic cells. It is the first line of defence against chemical, physical or infectious insults. It is usually referred to as the innate immune system. Though it is often considered as non-specific, we know today that dendritic cells, but also epithelial cells, specifically recognize molecular markers, called 'danger signals', which are present on the surface of pathogens. They are able to recognize them by means of receptors called 'pattern recognition receptors' [2]. This immediately operating immune response is classically opposed to the delayed or specific immune response which involves either antibodies synthesized by B or plasma cells, or T cells bearing a receptor specifically directed against the pathogen.

Immune-mediated inflammatory diseases are the result of those mechanisms. When the disease predominantly involves specific $\mathrm{T}$ cells or pathogenic antibodies, we refer to it as auto-immune disease. When the damage in a given disease is mainly the result from mediators of the innate immune system, we refer to it as auto-inflammatory disease. Table 1 and figure 1 give some examples of auto-immune and auto-inflammatory diseases as well as the main mediators involved in their pathogenesis. Some polygenic diseases rather involve auto-immunity and others rather auto-inflammation (fig. 1). But in reality, many diseases can involve both mechanisms, and actually we often do not know which mechanism predominates. Furthermore, during the course of a disease, some manifestations will rather be the consequence of autoimmunity and others of auto-inflammation. This is not surprising as dendritic cells for example are both, actors of the innate immune system and the cell type involved in educating/activating the specific immune system. So an important question is: how can we distinguish between auto-immunity and auto-inflammation? The answer to this question is crucial as it provides a rational basis to therapeutically target specific cell types (table 1).

\section{KARGER \\ Fax +41613061234 \\ E-Mail karger@karger.ch}

www.karger.com
(C) 2008 S. Karger AG, Basel

1018-8665/08/2164-0283\$24.50/0

Accessible online at:

www.karger.com/drm
Dr. Dan Lipsker

Clinique Dermatologique

1, place de l'Hôpital

FR-97091 Strasbourg Cedex (France)

Tel. +33 38811 6179, Fax +33 38811 5962, E-Mail dlipsker@noos.fr 


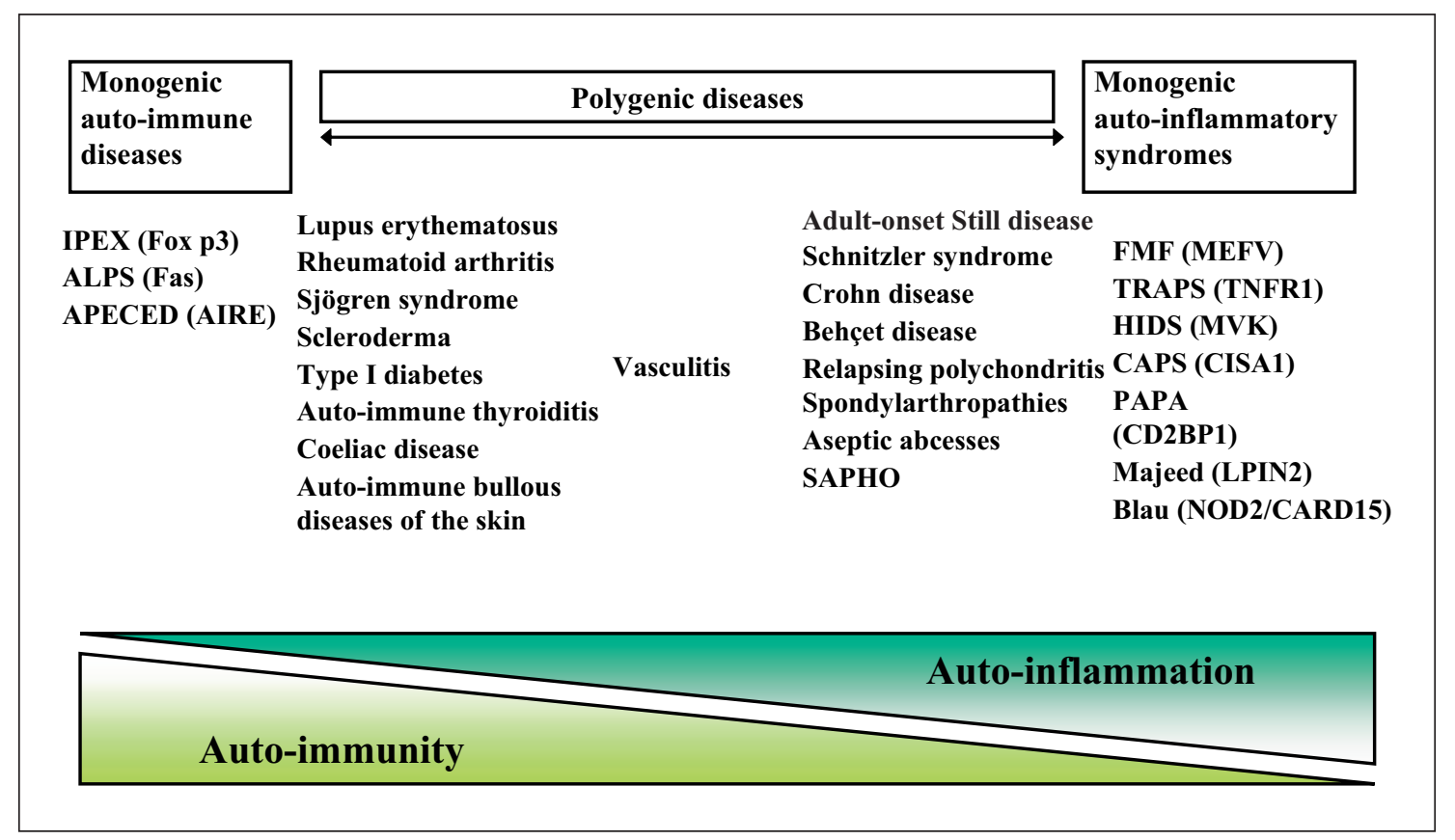

Fig. 1. Classification of inflammatory diseases according to the predominant involvement of auto-immune or auto-inflammatory disease mechanisms. FMF = Familial Mediterranean fever; MEFV = Mediterranean fever gene; TRAPS = TNF-receptor-1associated periodic fever syndrome; TNFR1 = tumour necrosis factor 1 receptor; HIDS = hyperimmunoglobulin D syndrome; MVK = mevalonate kinase CAPS = cryopyrin-associated periodic syndromes; CISA1 = cold induced auto-inflammatory syn- drome; PAPA = pyogenic arthritis, pyoderma gangrenosum and acne syndrome; $\mathrm{CD} 2 \mathrm{BP} 1=\mathrm{CD} 2$ binding protein 1 ; LPIN2 = lipin 2 gene; $\mathrm{NOD} 2$ = nucleotide oligomerization domain 2; CARD15 = caspase recruitment domain 15; IPEX = immunodysregulation, polyendocrinopathy, enteropathy, X-linked; ALPS = auto-immune lymphoproliferative syndrome; APECED = autoimmune polyendocrinopathy-candidiasis-ectodermal dystrophy; AIRE $=$ autoimmune regulator.

Table 1. Mediators, clinicopathological correlations and treatment of auto-immune and auto-inflammatory diseases

\begin{tabular}{lll}
\hline & Auto-immune diseases & Auto-inflammatory diseases \\
\hline $\begin{array}{l}\text { Mediators involved in } \\
\text { pathogenesis }\end{array}$ & T cells, B and plasma cells, antibodies & $\begin{array}{l}\text { Epithelia, neutrophils, dendritic cells, natural killer } \\
\text { cells, pro-inflammatory cytokines, complement, ... }\end{array}$ \\
\hline Typical skin manifestations & Dermatitis, alopecia areata, bullae & $\begin{array}{l}\text { Inflammatory plaques, urticaria, aphthous } \\
\text { stomatitis, conjunctivitis, erythema nodosum, } \\
\text { pyoderma gangrenosum, pustules }\end{array}$ \\
\hline $\begin{array}{l}\text { Histopathological findings } \\
\begin{array}{l}\text { Usually effective } \\
\text { symptomatic treatments }\end{array}\end{array}$ & $\begin{array}{l}\text { Lymphocytic and/or eosinophilic dermal infiltrate } \\
\text { alefacept }\end{array}$ & Neutrophilic dermal infiltrate \\
\hline
\end{tabular}

The main cutaneous findings suggestive of either auto-immune or auto-inflammatory pathomechanisms are summarized in table 1. For the dermatologist, it is noteworthy that the broad group of neutrophilic dermatoses suggest auto-inflammation. This conclusion can be drawn from the fact that neutrophilic dermatoses occur in many monogenic auto-inflammatory diseases. In this issue of Dermatology, Marzano et al. [3] report 3 new cases and summarize previously published cases of an entity called 'amicrobial pustulosis of skin folds'. Patients develop recurrent attacks of aseptic pustules in major and minor skin folds; involvement of skin between toes and 
of retro-auricular folds is highly suggestive. Interestingly, this entity is significantly associated with auto-immune diseases, especially lupus erythematosus (LE). Recurrent aseptic pustules suggest an auto-inflammatory disease mechanism. In this issue of Dermatology, Antille et al. [4] report their preliminary findings on the cytokine/chemokine pattern in the skin of a patient with amicrobial pustulosis of skin folds, as compared to other neutrophilic diseases. Using a protein array for more than 100 cytokines, they found that CD170 and the metalloprotease MMP-9 were highly expressed in the lesional skin of patients with different neutrophilic diseases whereas other cytokines show a different pattern among these different entities [4].

These observations may suggest that some cutaneous manifestations of LE involve an auto-inflammatory mechanism. LE is classically considered as a typical example of a polygenic auto-immune disease. Many facts support this assumption: patients bear auto-antibodies which are present years before disease onset [5], autoantibodies deposit in the skin and give rise to the classic lupus band, defects in the inhibitory Fc receptor, Fc $\gamma$ RIIB, have been shown to contribute to B cell activation and auto-immunity [6] and some MHC haplotypes confer a genetic predisposition to LE. On the other hand, deficiency in early components of the complement system, actors of the innate immune system, and some tumour necrosis factor receptor variants [7], key actors of the innate immune system, also confer a predisposition to LE. Moreover, it was shown that some pattern recognition receptors of the innate immune system, Toll-like receptors, could be involved in the pathogenesis of LE [8].

Thus, the clinical observations reported in this issue of Dermatology raise some important questions which should be addressed in the coming years. Does neutrophilic LE portend prognostic value? Do patients with neutrophilic LE have particular disease associations? Most importantly, could defective mechanisms in the innate immune system be the initial event in the pathogenesis of LE? The major pathogenic role of epithelia and the innate immune system was demonstrated in many inflammatory diseases in the past years. For example, the Sjögren syndrome, an exocrine endocrinopathy, also called auto-immune epithelitis, was for years considered as a primary auto-immune disease. Recent studies demonstrated early involvement of epithelia and the innate immune system, and it is considered that Sjögren syndrome could be a primary disease of defective epithelia [9]. Sjögren syndrome is strongly associated with, or could even merely be a variant of, subacute cutaneous LE.
Thus, its pathogenesis is certainly relevant to LE. Therefore, the role of the initial involvement of epithelia and the innate immune system in LE will have to be addressed and the pathogenesis of LE could possibly be rewritten in the coming years.

How should we interpret skin manifestations of LE? From a practical point of view, we should separate signs indicative of thrombosis from signs related to inflammation $[10,11]$. The specific signs of inflammation can be separated into dermo-epidermal, dermal and hypodermal variants of LE [12]. Many specific skin lesions in patients with LE are long-standing and characterized pathologically by a lymphocytic dermal infiltrate and/or mucin deposition, features that fit with an auto-immune pathogenesis. Deposition of immunoglobulins at the dermo-epidermal junction further supports this view. The often overlooked neutrophilic manifestations of cutaneous LE rather point to an auto-inflammatory pathogenesis. Experienced dermatopathologists are indeed aware of the fact that early and evolving lesions of cutaneous LE are pathologically characterized by a neutrophilic infiltrate [13]. Furthermore, some classic variants of LE are a neutrophilic disease, as for example bullous LE or urticarial vasculitis. Neutrophilic dermatoses, like pyoderma gangrenosum and Sweet syndrome, have been reported in LE patients, and they can even be the presenting manifestation of LE $[14,15]$. Amicrobial pustulosis of skin folds should be considered as a paradigm for such a neutrophilic pattern of inflammation, potentially involving predominant auto-inflammatory pathways and requiring dapsone therapy. We suggest to capture this under the new term of 'neutrophilic cutaneous lupus erythematosus'.

References

1 McGonagle D, McDermott MF: A proposed classification of the immunological diseases. PLoS Med 2006;3:e297.

2 Matzinger P: Tolerance, danger, and the extended family. Annu Rev Immunol 1994;12: 991-1045.

3 Marzano AV, Ramoni S, Caputo R: Amicrobial pustulosis of the folds: report of 6 cases and a literature review. Dermatology 2008; 216:305-311.

4 Antille C, Frei M, Sorg O, Tran C, Kaya G, Masouyé I, Fantao L, Prins C, Saurat J-H: Amicrobial pustulosis of the folds associated with auto-immune disorders: a case report with an analysis of cytokine expression profile in skin lesions of cutaneous neutrophilic lupus. Dermatology 2008;216: 324-329. 
5 Ackerman AB, Boer A, Bennin B, Gottlieb GJ: Histopathologic Diagnosis of Inflammatory Skin Diseases, ed 3. New York, Ardor Scribendi, 2005.

6 Waldman MA, Callen JP: Pyoderma gangrenosum preceding the diagnosis of systemic lupus erythematosus. Dermatology 2005;210:64-67.

7 Gleason BC, Zembowicz A, Granter SR: Non-bullous neutrophilic dermatosis: an uncommon dermatologic manifestation in patients with lupus erythematosus. J Cutan Pathol 2006;33:721-725.

8 Lipsker D: Classification of specific manifestations of cutaneous lupus erythematosus: a time for change? The concept of dermal lupus erythematosus. Dermatology 2006;212: 324-326.
9 Arbuckle MR, McClain MT, Rubertone MV, Scofield RH, Dennis GJ, James JA, Harley JB: Development of autoantibodies before the clinical onset of systemic lupus erythematosus. N Engl J Med 2003;349:1526-1533.

10 Mackay M, Stanevsky A, Wang T, Aranow C, Li M, Koenig S, Ravetch JV, Diamond B: Selective dysregulation of the FcyIIB receptor on memory B cells in SLE. J Exp Med 2006; 203:2157-2164.

11 Morita C, Horiuchi T, Tsukamoto H, Hatta N, Kikuchi Y, Arinobu Y, Otsuka T, Sawabe T, Harashima S, Nagasawa K, Niho Y: Association of tumor necrosis factor receptor type II polymorphism 196R with systemic lupus erythematosus in the Japanese: molecular and functional analysis. Arthritis Rheum 2001;44:2819-2827.
12 Papadimitraki ED, Choulaki C, Koutala E, Bertsias G, Tsatsanis C, Gergianaki I, Raptopoulou A, Kritikos HD, Mamalaki C, Sidiropoulos P, Boumpas DT: Expansion of tolllike receptor 9-expressing B cells in active systemic lupus erythematosus: implications for the induction and maintenance of the autoimmune process. Arthritis Rheum 2006; 54:3601-3611.

13 Mitsias DI, Kapsogeorgou EK, Moutsopoulos HM: Sjögren's syndrome: why autoimmune epithelitis? Oral Dis 2006;12:523532.

14 Lipsker D: The importance of thrombosis in patients with lupus erythematosus. Dermatology 2006;212:214-215.

15 Lipsker D, Mitschler A, Grosshans E, Cribier B: Could Jessner's lymphocytic infiltrate of the skin be a dermal variant of lupus erythematosus? An analysis of 210 cases. Dermatology 2006;213:15-22. 